Keywords: religion, identity, monotheism, sacrum, profanum, social space, cultural artifact, communicative code, Christianity, Judaism, Islam.

УДК $130.2(470+571)$

DOI: $10.32340 / 2414-9101-2021-2-44-48$

О. В. Первушина, кандидат культурологии, доцент Алтайский государственный институт культуры (Барнаул, Россия) agaki-pervushina@yandex.ru

\title{
КОНЦЕПТЫ «ЧЕЛОВЕК», «ПРИРОДА» И «КУЛЬТУРА» В ОТЕЧЕСТВЕННОЙ ИСТОРИКО-КУЛЬТУРОЛОГИЧЕСКОЙ МЫСЛИ: ПРОСТРАНСТВЕННЫЙ АСПЕКТ
}

Аннотация. Раскрыто содержание центральных для отечественной философской, геосоциокультурной и историко-культурологической мысли категорий «человек», «природа», «культура», рассматриваемых в качестве базовых для русской ментальности концептов, отражающих актуальный культурфилософский духовный опыт народа. Охарактеризована специфика смысловой и символической интерпретации этих концептов в отечественной исследовательской традиции.

Ключевые слова: человек, природная среда, культура, знаково-символическое пространство культуры, «месторазвитие», гибридная идентичность, универсальные культурные иенности.

Одной из проблем, определяющей современный культурологический дискурс является проблема соотношения понятий «человек», «природа», «культура», их единство, взаимосвязь, обусловленность и вместе с тем противоречивость и неоднозначность взаимосвязи и взаимоопределенности в современном мире. Пройдя в своем эволюционном развитии и становлении этапы неразрывного единства с миром природы, когда, вероятно, человек рассматривал себя как неотъемлемую часть окружающего мира до выделения из природного окружения и активного воздействия на природную среду путем построения своего антропогенного мира, часто необдуманно и недальновидно враждебного природному окружению, человек остается по-прежнему и телесно и пространственно частью природной среды. Очевидно, что человек современной инновационной культуры, живущий в пространстве искусственных объектов, знаков и «симулякров» (по Ж. Бодрийяру) потерял связь с природной средой, которая являлась пространством его жизнедеятельности на протяжении тысячелетий, определяя потребности насущного существования, сохранения и воспроизводства. Принимая этот неизбежный результат эволюции человека как вида, реализующего потенциал стремления к усложнению условий внеприродного бытия, французский культуролог и социолог Ж. Бодрийяр пишет о потерянности человека в этом мире искусственных предметов и вещей, в котором и он сам становится «симулякром»- искусственным знаково-символическим объектом. «Вещи, - пишет Ж. Бодрийяр, - не составляют ни флоры, ни фауны...впечатление размножающейся растительности или джунглей, где новый дикий человек современности с трудом отыскивает вновь проявления цивилизации»[1, с. 6-7]. В этом контексте имеет смысл обратиться к проблеме соотношения человеческого, природного и культурного в традиции русской философии второй половины XIX - начала XX вв. Это наследие сегодня приобретает особый смысл и значение духовного опыта, не утратившего своего значения по истечению времени.

«Человек», «Природа», «Культура» всегда были в центре отечественной философской, геосоциокультурной, историко-культурологической мысли. Эта тема одна из ключевых в культурфилософских трудах Н. Я. Данилевского, Н. А. Бердяева, С. Л. Франка, И. А. Ильина, П. А. Флоренского, П. Н.Савицкого. На наш взгляд, в этих исследованиях представляет интерес категория 
«пространство», которая позволяет обратиться к данной проблеме с позиций культурологического анализа, что связывает воедино человека, природную среду и культурную среду, им порожденную. Пространство как природная среда, система социальных отношений и мир творимых человеком знаково-символических культурных реалий образуют единое целое, в котором природное начало, с точки зрения русской культурфилософской мысли носит определяющий характер ментальности этноса.

Вопрос о цивилизационной принадлежности страны в контексте дискуссии «Россия - Запад» (П. Я. Чаадаев, С. М. Соловьев) нашел развитие и воплощение в известной концепции Н. Я. Данилевского о культурно-исторических типах в работе «Россия-Европа». Законы формирования, движения и развития культурно-исторических типов он рассматривает в неразрывной связи с природно-географическим пространством страны. Н. Я. Данилевский пишет о том, что «... вошло в жалкую моду говорить, что Россия довольно, даже слишком велика...Дуб и в три обхвата толщиной и в пятнадцать сажень вышиной еще нельзя назвать слишком большим, переросшим свои нормальные размеры!...Государство «достигнет полного своего роста, только когда соединит воедино весь тот народ, который его сложил, поддерживает и живит его» и «...устья рек, орошающих ее почти на всем протяжении их течения, и устья своих внутренних морей...» [2, с. 568-569]. Н. Я. Данилевский природно-географическое пространство России рассматривает в тесной связи с культурной деятельностью этноса, который адаптируется к пространству, осваивает в соответствии со своими нуждами и вместе с тем пространство определяет жизнь этноса, способы консолидации, «собирание элементов своего богатства и могущества» [2, с. 569]. Эту тему далее развивает целая плеяда великих русских философов, многие из которых (Н. А. Бердяев, Н. С. Трубецкой, П. Н. Савицкий), покинув Родину не по своей воле, продолжали писать в изгнании об историко-культурном самоопределении России и русском культурном мире как уникальном образовании, где природное, человеческое и культурное составляет особую целостность, образуя уникальное пространство.

Н. А.Бердяев в своем известном философском труде «Судьба России» рассматривал необъятные российские пространства как ключевой фактор, определивший историю, судьбу народа и отечества, выбор пути и ценностные приоритеты русского человека. Он пишет, «...что в судьбе России огромное значение имели факторы географические, ее положение на земле, ее необъятное пространство» [3, с. 95]. По мысли Н. А. Бердяева роль и образ российского пространства в сознании русского человека исторически определяли его ценностные установки в контексте различных временных периодов, оказали колоссальное внимание на историческую судьбу отечества. Особенность подхода ученого к анализу пространства состоит в том, что оно рассматривается не только и столько как природная среда, но и как знаково-символическое образование, как «внутренний, духовный фактор в русской судьбе», география «русской души» [3, с. 98]. Безбрежность и бесконечность пространственных констант окружающей человека природной среды оборачиваются знаково-символическими константами, определяющими особый строй души русского человека: в его сознание «... вошли и безграничность русского пространства и безграничность русских полей» [3, с. 97]. Н. А. Бердяев рассматривает взаимоотношения русского человека и пространства как наполненные драматизмом и противоречивостью. В этом контексте пространство не только условия и среда существования, отношения с которым выстраиваются по принципу «субъект» - «объект» (освоение, приспособление и воздействие, исходя из прагматических целей), пространство наделяется собственной автономностью и субъективностью, субъект-человек воздействует на пространство, воспринимая его как самостоятельную силу в своей судьбе, а пространство требует от субъекта-человека не только определенной степени адаптации, но и защищает, укрывает, спасает от врага, тем самым оно тоже воспринимается как субъект. С одной стороны, в безбрежности бесконечных российских пространств можно затеряться, отдавая им свою энергию и силу, но с другой стороны, пространство - надежда русского человека на безопасность и спасение, не только физическое, но и духовное [3, с. 99]. Интересен факт психологического переживания человеком пространства, интериоризации его образа во внутренний мир, устойчивость этого переживания, укоренение его во многих поколениях русских людей. Константы «земля», «судьба», «душа» 
являются взаимозависимыми и образующими по мысли философа, единое целое. «Земля» определяет характер деятельности человека и его духовные устремления, формирует «душу» как особый ценностный строй, а «душа» русского человека определяет его личную «судьбу» и «судьбу» России.

Близка размышлениям Н. А. Бердяева идея «патриотизма», понимаемая русским религиозным философом И. А. Ильиным как личностное качество, определяющее глубинную связь в душе человека природного, социального начал; духовного родства, солидарности с ближними и чувства защищенности, укорененности в совместное творимое человеком и его ближними бытие в пространстве, которое и есть это единство. Философ размышляет о том, «...что жизнь человека на земле подчинена пространственно-территориальной необходимости» [4, с. 232]: особенности климата, территориальная протяженность, природный ландшафт порождают разные способы хозяйствования, традиции, обычаи, а значит и разные формы солидарности людей - «...примкнуть к одной группе, значит, противопоставить себя остальным. Общественная солидарность и общественная противоположность связаны друг с другом и обусловлены друг другом...» [4, с. 233]. Необходимость выживания, приспособления к жизненным условиям требует солидарности, объединения с другими людьми, живущими в этих условиях. И. А. Ильин пишет о том, что «... человек должен жить и трудиться оседло; и эта оседлость...прикрепляет человека» к земле, «...заставляет его войти в организованные волевые союзы местного характера», а это в свою очередь формирует связи и отношения между людьми, живущими на одной земле на основе солидарности, формирует параметры отношений, создающие психологическую основу для проявления и утверждения патриотического чувства. Соответственно «патриотизм» оказывается, по-видимому, необходимым, целесообразным и жизненно полезным» [4, с. 232-234]. И. А. Ильин акцентирует внимание на том, что патриотическое чувство нельзя свести к форме адаптации человека к условиям существования как биологического вида или как существа социального, философ, прежде всего, исследует духовную основу этого чувства, что наделяет особым смыслом понятие «пространство» как место многопоколенного сосуществования людей, которые «... инстинктивно, естественно и незаметно привыкают к окружающей их среде, к природе, к соседям и культуре своей страны, к быту своего народа» [4, с. 235]. Но, вместе с тем он в глубинной привязанности человека к своей земле видит не биологический инстинкт, а проявление глубинной духовной силы рода: «Нельзя человеку жить на земле без инстинкта, без этой таинственно-целесообразной, органически-мудрой, бессмысленно-страстной Силы, от Бога дарованной и от природы нам присущей - силы, строящей и личное здоровье, и приспособление к природе, и хозяйственный труд, и брак, и жизнь семьи, и историю народа» [4, с. 238]. И. А. Ильин подчеркивает духовные истоки формирования патриотизма, обращая внимание, что взятые сами по себе территория, климат, расовое происхождение, ни совместное проживание людей еще «...не составляет Родину» [4, с. 241-242]. Но если данное пространство в совокупности своих элементов, образующих неповторимую и уникальную целостность, наполняется духовным значением с точки зрения этноса, создающего национальную культуру, оно будет рассматриваться патриотами как священное. Таким образом, философ понимает пространство, где соединяется природное и человеческое как особого рода реальность, которая формируется только культурой как внебиологической деятельностью человека, дает пространству особое качество - духовное измерение.

Идея пространства становится одной из ключевых в философии одного из ведущих представителей евразийского движения, геополитика, историка, культуролога П.Н.Савицкого и находит выражение в концепте «месторазвитие». В современном социально-гуманитарном знании «месторазвитие» П. Н. Савицкого в основном рассматривается с позиций философского, исторического, геополитического подходов и в меньшей степени с позиций культурологического, антропологического анализа.

«Месторазвитие» по представлению П. Н. Савицкого имеет методологическое значение и структурно представляет собой «пространственно-временной континуум»; данный концепт изначально обозначает идею пространства. «Месторазвитие» сложный термин, состоящий из двух лексем «место» и «развитие», первое семантически связано с топосом, второе заключает в себе 
движение к какому-либо состоянию, т. е. время. Эта категория проявляет себя посредством единства природно-географического, социально-исторического, социально-культурного и территориального факторов. П. Н. Савицкий полагал, что изначально человеческие общества, проживая на определенной земле, образуют с ней единое целое, землей порожденное и эту землю поддерживающие, являясь своего рода «общежитиями», строящимися на основе «генетических вековечных связей...между растительным, животным и минеральными царствами, с одной стороны; человеком, его бытом и даже духовным миром - с другой»[5, с. 282]. В этих общежитиях элементы «взаимно приспособлены друг к другу и находятся под влиянием внешней среды, под властью земли и неба» и взаимно определяют друг друга, тем самым создавая уникальное пространство данной культуры. Пространство, по мнению, П. Н. Савицкого определяет: «Взаимное приспособление живых существ друг к другу в тесной связи с внешними географическими условиями создает свой порядок, свою гармонию, свою устойчивость» [5, с. 282]. Таким образом, понятие «пространство» обладает не только характеристиками территориальной протяженности, включающее объекты ему соответствующие в силу материальной, биологической, климатической, географической принадлежности и обусловленности, но пространство так же имеет знаково-символическое измерение как результат культурной деятельности человека. Пространство переживается человеком как смысловая реальность, как мир творимый человеком в силу его способности к знаково-символической деятельности, и вместе с тем как некая данность - территории, климата, растений, живых организмов, ее населяющих.

Особое значение приобретает идея «месторазвитие» в современном техногенном мире, в котором связи природной среды, человека и культуры многократно опосредованы целями пользы, выгоды, когда духовным скрепам не остается места. Н. А. Бердяев обращает внимание именно на данную проблему, которая приобрела особую актуальность в наше время.

На гигантском временном пространстве антропогенеза Н. А. Бердяев выделяет следующие основные периоды отношения человека к природе, имеющие культурные измерения: погружение человека в природную среду; выделение из природной среды и адаптация с целью приспособления к особенностям экосистемы, мифологизация природной среды; овледение природной средой через познание ее законов, расширение антропосреды в результате борьбы с природой; «восстановление связи человека с душой природы и духовное овладение природой» [3, с. 225]. Последний этап в этом построении понимается как достижение идеального состояния гармонии души человека с окружающей средой, состояния, которое отличает идея абсолютной ценности слияния природного, человеческого и культурного на основе безусловной значимости данной гармонии для экологической безопасности и сохранения человека как вида, что исключает деструкции, прагматичность, практицизм, преследующие цели подчинения, получения выгоды и отношение к природе только как к ресурсу. На это обращали внимание П. А. Флоренский, К. С. Леонтьев, С. Н. Булгаков, утверждая, что именно в православии определяющей предстает идея благословения Богом любой твари, всего живого: идея «святости твари». П. А. Флоренский в работе «Столп и утверждение истины» писал: «...замечательно совершенное тождество Божьего завета с человеческой и прочей тварью. Это не два различных завета, это один завет со всем миром, рассматриваемым как единое существо, возглавляемое человеком... Только в христианстве тварь получила свое религиозное значение, только с христианством явилось место для «чувства природы», для любви к человеку и вытекающей отсюда науки о твари [6, с. 272-273]. Таким образом, траектория отношения человека и природы выстраивается как движение от подчинения, борьбы и овладения природным до осознания возможности иного отношения, основанного на «восстановлении связи человека с душой природы».

В рамках современной техногенной культуры отношения человека и природы на уровне духовных ценностных измерений представляются проблематичными и пока недостижимыми. Возникает вопрос о роли «месторазвития» как такового в судьбе человека, который часто не идентифицирует себя с породившим его топосом, так как высокая мобильность, перемещение по разным культурным пространствам не актуализируют в данной системе ценностей связь с 
«месторазвитием», порождая гибридную идентичность, которая носит универсалистский характер и не связывает человека с определенным системообразующим для него типом культуры. Это так же вызвано тем, что пространство бытия человека эпохи постмодернизма является преимущественно знаково-символическим, информационно-знаковым, тем самым он в большей степени, чем его предки, жившие в предметно-вещественной среде, отдален от природного окружения, которое он воспринимает как реальность, которая влияет на его жизнь многократно опосредованно или функционально как источник потребляемых ресурсов. Но данная ситуация проблематична тем, что прагматичность отношения к природной среде не только разрушает гармоничные отношения человека и природы, она становится источником кризиса и разрушения самой культуры. Современная глобальная культура как транслятор универсальных ценностных моделей поведения, способов коммуникаций и создания востребованных массовым сознанием текстов, формирует специфическое знаково-символическое пространство, которое в большей степени является техногенным, чем культурным в смысле индивидуального авторства художника, музыканта, артиста, писателя, философа, воплощающих образ мира посредством рефлексии, художественного видения и духовного опыта. Сохранение гармонии и единства человека с природой тесно связаны с проблемой сохранения культуры. Человек, природа, культура образуют единое целое и с разрывом, разрушением этих глубинных взаимосвязей возникает опасность исчезновения, модификации человека и на уровне сознания и как биологического вида, превращение его в человека-функцию, человека - техническую монаду.

\title{
Список литературы
}

1. Бодрийяр, Ж. Общество потребления. - Москва : Изд-во АСТ, 2020. - 320 с. - (Философия - Neoclassic).

2. Данилевский, Н. Я. Россия и Европа // Классика геополитики. XIX век : [сб. ст.] / сост. К. Королев. - Москва : АСТ, 2003. - 718 с.

3. Бердяев, Н. А. Судьба России. - Москва : АСТ, 2005. - 333 с.

4. Ильин, И. А. Путь духовного обновления. - Москва : Альта-Принт, 2006. - 450 с. - (Православная литература).

5. Савицкий, П. Н. Континент Евразия. - Москва : Аграф, 1997. - 461 с. - (Новая история).

6. Флоренский, П. А. Столп и утверждение истины : [в 2 т.]. - Москва : Правда, 1990. -

Т. 1, кн. 1. -496 c.

Olga V. Pervushina, Ph. D. in Cultural Studies, Associate Professor Altai State Institute of Culture (Barnaul, Russia) agaki-pervushina@yandex.ru

\section{CONCEPTS "HUMAN", "NATURE", “CULTURE" IN RUSSIAN HISTORICAL AND CULTURAL THOUGHT: SPATIAL ASPECT}

\begin{abstract}
The article discloses content of key for Russian philosophical, goesociocultural, and hictorical thought terms "a human", "nature", "culture" considered as basic concepts for Russian mentality that reflect the people's cultural and philosophical experience. The author outlines semantic meaning and symbolic interpretation of concepts mentioned above in Russian research tradition.

Keywords: a human, natural environment, culture, sign-simbolic space of culture, "locally determined progress", hybrid identity, common cultural values.
\end{abstract}

